\title{
Editorial: The emphasis is on the "and": new directions for Society and Business Review
}

I am delighted to share my first editorial of Society and Business Review (SBR). I stepped in as the editor-in-chief of the Journal in 2020, as a scholar and a professor of corporate social responsibility (CSR), sustainability, responsible management education and volunteering. As the past editor of Business, Peace and Sustainable Development, and as an academic who published extensively on these topics, I was grateful when Emerald Publishing and Dr Daniel Ridge offered me this important role.

I would first like to acknowledge the past editors of SBR and the many outstanding scholars who served on its editorial board. SBR has been operating for 15 years, published hundreds of articles in many regular and special issues. As academics, we always stand on the shoulders of the giants and scholars who came before us, and I would like to acknowledge everyone who contributed to SBR to date.

I would also like to welcome aboard the many new members of our strong editorial board. Led by experts in the field of business and society, our editorial board members help us lead the Journal forward. Together with several existing members of the editorial board, I am very proud of the leadership of SBR. I would also like to express my gratitude to the members of the review board and to all our reviewers who extract the much-needed time and effort to review submissions and ensure the quality of SBR. No academic journal can succeed without this voluntary support, and for this, I am grateful. Since I became the editorin-chief, I have seen nearly one hundred submissions and I would like to thank all the authors who contributed to SBR.

With my aspiration to improve SBR and enhance it, I have led a few substantial changes to the Journal, which will guide us in the future. First, the aims and the scope of SBR were altered so that it better captures the emerging discourse on business and society. If in the past SBR published articles on business only or society only, we are now more interested in the "and" part of business and society.

The Journal is currently aimed "to cultivate and share knowledge and ideas to assist businesses and organizations to enhance their commitment to society and the planet." Drawing on a wide range of theoretical and methodological approaches to stimulate substantive debates, SBR produces a rich stream of conceptual and applied research focused on practical developments in the field of business and society. The Journal particularly encourages scholarly work on the impact of changing business/corporate social concerns and practices on people, the sustainability of different economic activities, the impact of corporations and business education on society, and how societal issues come to shape business activities.

As such, our scope changed to include the following topics:

- CSR social responsibility, corporate responsibility, corporate social performance;

- new theories and models on CSR, business ethics and sustainable development;

- international business and global social issues (e.g. modern slavery);

- corporatization of politics, politicization of corporations and corporate political activism;

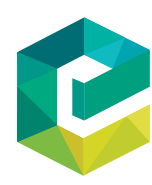

Society and Business Review Vol. 16 No. 2, 2021 pp. 153-155 
SBR

16,2

- corporate social impact: measurement, communication and reporting;

- business ethics and organizational values;

- business schools and society, responsible management education;

- business strategies, sustainable development and ecological prosperity;

- business and the sustainable development goals; and

- stakeholder theory, stakeholder integration.

When discussing CSR, it is important that contributors take a more holistic approach to the responsibilities of the company or companies they discuss. The research and practice of CSR have transformed over the past decade with many discussing the shift from corporate philanthropy to a mindset and a worldview, embedded in every aspect of the organization (Aguinis and Glavas, 2013; Haski-Leventhal, 2018). For this purpose, I would like to offer a new definition of CSR:

Strategic CSR is a holistic and long-term approach to the responsibility and role of business in society, based on stakeholder integration and ethical behavior, and utilizing the firm's resources and brand to address societal and environmental issues.

Many of the other aims and scope detailed earlier, therefore, fall under this definition: stakeholder management and integration, business ethics, social issues and climate action. When companies adopt a broad view of their responsibility and role in society instead of a narrow one (i.e. maximizing shareholder value), there is no limit to what can be achieved. If corporates use who they are and what they have - their power, resources and knowledge - to address society's greatest problem, there is no reason to leave behind political activism and issues such as modern slavery.

The role of business in society is ever evolving. For centuries many believed that the only responsibility of companies is to maximize profits and shareholder value and that the business of business is business. The only contribution business should have to society is through employment, products and service provision and economic growth. Echoed by Milton Friedman and his followers in research and practice, this comes at an enormous cost to humanity and the planet. With the idea of externalities, businesses often washed their hands off any negative impact they may have had on society and the environment because as long as the economy thrived, it was all fine. In the 1980s and the 1990s, the business sector discovered that random acts of charity and some sustainability PR could help promote brands and sell more products. This was seen by many as the early stages of CSR, but it is only the other side of the same Friedman Coin. Only when businesses started to truly see their role in society as an integrated one, where the company is closely connected, for better or worse, to the rest of the world, did CSR truly emerge. While early pioneers such as Ben and Jerry's and Patagonia paved the way, it is only in the past two decades that we see companies taking a more holistic approach to their role in society and the community and their social and environmental responsibility.

A good analogy can be found in fishing. In the first stage of the evolving role of business and society, businesses were only selling fish. In the second stage, they were giving fish to the poor. In the third stage, they were teaching people how to fish so that they can eradicate poverty. The last stage is about disrupting the fishing industry, asking why is it that so many people have no fair access to fishing and what can we do to change this, perhaps by 2030.

My aspiration for $S B R$ is, therefore, to create a platform where these crucial shifts in the connections between business and society are discussed and portrayed, particularly in parts of the world where such issues are not often covered by other similar journals. In my first ten months in this role, I received many submissions that only dealt with a social issue or 
only focused on a business issue. These articles were not seen as a good fit for SBR. It is the articles that examine the connection between the two, preferably in an innovative way, that align with our goals, aims and scope.

The previous year has been very challenging and with immense impacts on business, society and academia the world over. Some companies rose up to the challenge and used their CSR and sustainability to help address some of the impacts of COVID-19. From corporate philanthropy (e.g. Crocs donating millions of shoes to medical teams around the globe) to developing treatments and vaccines, many businesses showed that in times of need, they can be a force for good. Moreover, if there is anything we can learn from this global pandemic, is how we can work together and connect, as humans and as organizations, to address some of the most difficult challenges that we face. In the spirit of this human capacity, I am proud to present this issue of Business and Society.

This issue of SBR offers nine new articles on some aspects of business and society. To illustrate, Anis Jarboui et al. write about the way that CEO overconfidence and narcissism affect CSR, while also examining the important role of corporate governance. An article by Rajibul Ahsan and others shed light on environmental goods, examining how products of the green economy can present the business world with an immense opportunity together with some challenges. Understanding both can not only help business keep their competitive advantage but also increase their own and overall sustainability. The third article in this issue by Kachouri Maali and her colleagues investigates the direct and indirect links between corporate governance and sustainability performance using CSR. Their study shows that CSR fully mediates the relationship between corporate governance and sustainability performance in UK firms. As a final example of the papers in this issue, I would like to mention a paper by Preshita Neha Tudu who writes about whistleblowing. This paper aims to understand an employee's intention toward whistleblowing by analyzing Ajzen's theory of planned behavior and Graham's principled organizational dissent. In doing so, it has an important contribution to the discourse on business ethics.

Together, these papers and others offer a fascinating variety of different points of view on the role of business in society, by connecting various aspects, issues and cultures. I am delighted to share this issue with the readers of $S B R$, and I look forward to many more submissions and issues in the future.

\section{Debbie Haski-Leventhal Macquarie Business School, Macquarie University, North Ryde, Australia}

\section{References}

Aguinis, H. and Glavas, A. (2013), "Embedded versus peripheral corporate social responsibility: psychological foundations", Industrial and Organizational Psychology, Vol. 6 No. 4, pp. 314-332.

Haski-Leventhal, D. (2018), Strategic Corporate Social Responsibility: Tools and Theories for Responsible Management, Sage, London.

\section{Further reading}

Matten, D. and Moon, J. (2008), "Implicit' and 'explicit' CSR: a conceptual framework for a comparative understanding of corporate social responsibility", Academy of Management Review, Vol. 33 No. 2, pp. 404-424. 